\title{
Life Cycles and Carrying Capacities in Tourism
}

\author{
Ralf Buckley \\ International Centre for Ecotourism Research, Griffith University, Australia \\ r.buckley@griffith.edu.au
}

If I understand correctly, Sagar Singh argues that the concept of carrying capacity has the potential to be a key unifying theme in tourism research. He thinks that it was introduced too early to be accepted, and abandoned before its potential was realised. And he argues that the concept of a stable carrying capacity can be reconciled with the concept of an evolving destination area, by subdividing carrying capacities into different types and timescales.

His rationale, which I fully endorse, is that tourism research is far too heavily influenced by postmodernism, post-structuralism and similar constructs in the academic social sciences, which have little to do with the realities of tourism either as a commercial business or an individual activity. Selling goods and services to people travelling for social reasons - it's not that complicated a concept, surely.

As Singh himself notes, almost all research concepts in tourism are derived from other disciplines. The concept of carrying capacity is derived from stocking rates in agriculture, life cycles from biology, recreational succession from ecological succession in plant and animal communities. And why not, if concepts from one discipline can be applied meaningfully to illuminate another? It is only when the terminology of a concept, but not the underlying concept itself, is transferred from one discipline to another that difficulties in understanding arise. Chaos theory provides a good example: it has a well defined mechanistic and mathematical basis in physics, but is at best a vague analogue in tourism.

The distinctions between ecological, social and economic meanings and measures for carrying capacity, and the limitations of each, have been well explored previously (Buckley 2000). They are useful as concepts but not as magic management numbers. Tourists do indeed produce environmental impacts (Buckley 2004), and there are many ways to manage them. Unlike grazing livestock, however, individual people have very different ecological impacts, because of differences in technologies and behaviour. Approaches which acknowledge this, such as ROS/LAC and its more sophisticated derivatives, are more useful.

Social carrying capacities, as noted by Sagar himself are inextricably entangled with issues of cultural change, community dynamics and divisions, and individual psychologies and perceptions - all matters which form the meat for many of the social sciences. Occasionally, as Sagar notes, an entire town may first encourage tourists and later turn against them. Much more commonly, however, tourism is favoured by those locals who experience a net benefit from tourism, and opposed by those who experience a net loss.

This applies in developed as much as developing nations. In Queensland's Gold Coast, for example, some local businesses and residents are in favour of major tourist events such as the "Indy" car race, whereas others oppose them. In Byron Bay, an hour south in northern New South Wales, some long-term locals and even local government officials continue to make the somewhat fantastic claim that Byron should not become a tourist township, whilst in reality it now has over 120 tourists for every ratepayer, and its economy and rate base are entirely supported by tourism and associated amenity migration. 
Economic carrying capacities should be easiest to define, since unlike environment or society, money can be measured meaningfully using a single unit. Since economic opportunities depend so heavily on social circumstances, however, the idea of an economic carrying capacity seems to be meaningful only if nothing else changes. In practice, this applies only at very short time-scales.

The issue of infrastructure has also been raised, by Sagar as well as others. It hardly needs noting that infrastructure reduces some impacts, both social and environmental, but creates others. This applies both at the scale of backcountry tracks and toilets in remote conservation reserves; or highways, sewage works and power stations in major metropolitan areas.

So how does this tie in with destination area life cycle? There are many different reasons why a particular tourist destination may attract more, or fewer, tourists at one time than another. Some of these factors are external, such as transport costs, political stability and safety, and fickle fashions amongst tourists themselves. Others are internal, and may indeed be generated at least partly through changes in tourist visitation rates themselves, through various forms of feedback mechanism including environmental, social and cultural changes.

The idea that many tourist destinations pass through a similar and perhaps cyclic evolutionary process was indeed a valuable insight when first applied to early English destinations designed specifically to attract tourists, in contrast to areas where tourism grew up around existing attractions. It was, however, a concept rather than a testable theory. Other tourism researchers have certainly seemed eager to impose it upon destinations of all kinds (Butler, 2006). None of this effort, however, seems to have yielded a revised model of any real predictive power, or statistically reliable tests to determine what factors drive the different hypothetical evolutionary pathways.

So, are Sagar's conclusions correct or not? Firstly, is carrying capacity a useful concept at all in tourism? Certainly. Is it "a unifying basis for tourism social science” (Sagar)? I don't think so. It was useful to point out, certainly, that tourism cannot continue to grow unchecked without creating environmental, social and economic impacts which could themselves deter tourists and affect commerce, communities and conservation. It was useful for academic analysts to point this out, because tourism promotion agencies were acting as though tourism somehow yielded only benefits, with no costs. Indeed, in many parts of the world they still do. To put forward carrying capacity as a core component of future tourism research, however, even that focussing on so-called sustainability, seems to me a retrograde step.

Secondly, can carrying capacity be reconciled with destination lifecycles, as Sagar suggests? Certainly, if only since both concepts are so loosely defined. If we acknowledge that carrying capacities can change over time, albeit with attendant social and environmental change, then there are no fundamental incompatibilities. And this is not a perversion of the original concept of carrying capacity. The density of stock which a given pasture can support can be reduced by drought or overgrazing, or it can be increased using fertilizer or exotic pasture species. Each of these has broader impacts. There are parallels, albeit imperfect, with the ideas of recreational succession. So, certainly, the effective capacity of a destination can change over time (Lawton, 2000). What other insights do we gain by linking these concepts?

To understand the development of tourism destinations, surely we should first analyse actual development trajectories of different destination areas subject to different circumstances, and 
then endeavour to extract general patterns? Should we not aim to match theory to facts, rather than the reverse?

There seems to me to be a strange paradox in the social sciences at present, at least as applied to tourism research. It is apparently acceptable to publish a personal story of one's own or someone else's experiences, under the name of phenomenology or qualitative research. To publish any kind of systematic observations which might qualify as objective or quantitative data, however, it seems that they must first be fitted to some pre-existing published theory, preferably one described in its own set of specialist jargon.

Understanding people and societies is of enormous and immediate practical value, in attempting to improve the wellbeing of current human populations and the continued existence of their successors. And certainly, there are many aspects of human experience which are more accurately described in words than numbers. But tourism is relatively simple, either as an industry sector or a social phenomenon. Our understanding is not advanced by making it appear more abstruse than necessary.

Singh has successfully woven a range of disparate sources and discourses into his plea. The ways in which he has done so are, perhaps, strangely phrased and somewhat confusing, but that is of secondary importance. His argument that tourism need not concern itself with disciplinary jargon and "isms" in the social sciences I fully endorse. His suggestion that carrying capacity is sufficient as a unifying theoretical basis for tourism studies, however, is harder to accept

\section{References}

BUCKLEY, R. 2000. An ecological perspective on carrying capacity. Annals of Tourism Research, 26: 207-210.

BUCKLEY, R. 2004. Environmental Impacts of Ecotourism. CABI, Oxford.

BUTLER, R. (ed.) 2006. Tourism Area Life Cycles (2vv). Channel View, Clevedon.

LAWTON, L. 2000. Public protected areas. In Weaver, D. (ed.) Encyclopaedia of Ecotourism. CABI, Oxford. 